\title{
OS SERTÕES: UMA EPOPÉIA EDUCADORA DE 100 ANOS
}

Euclides da Cunha imortalizou a epopéia do homem do sertão contra a miséria, a humilhação e o latifúndio

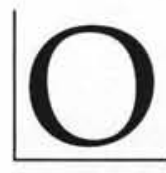

s sertões, de Euclides da Cunha, comemoram um século. A importância da obra está sendo lembrada este ano em todo o Brasil através de congressos, seminários e encontros, assim como da publicação de matérias na imprensa, livros e artigos. O alinhamento da revista Comunicação \& Educação neste conjunto de atividades revela a sintonia da publicação com um fato cultural de significado ímpar.

É oportuno lembrar que a chamada pós-modernidade, com os seus ritmos ditados pelos computadores, pela internet, pela televisão, não conseguiu, entre nós, arrefecer os gritos dramáticos e lancinantes que teimam em ecoar d' $O s$ sertões, ainda incomodando pela denúncia da agressão, da intolerância com a diferença, com o drama decorrente do atraso e da miséria. Graças à escrita nervosa e paradoxal de Euclides da Cunha, prosseguimos reconhecendo como a nossa centenária lógica das desigualdades, da exclusão e do abandono de milhões de pessoas sobrevive às inovações tecnológicas e ao frisson provocado pela chamada sociedade global.

$\mathrm{O}$ livro vingador, maneira pela qual Euclides da Cunha designava Os sertões, precisa ser lido ou relido, caso tenhamos a pretensão de entender como se deu a construção de nossa nacionalidade. A comunidade imaginada pelo autor de Contrastes e confrontos ${ }^{l}$, certamente haveria que superar o atraso e a miséria não por força dos canhões e da violência do Estado contra a sociedade, mas, entre outras medidas, pela ação dos professores, da escola e da educação.

1. CUNHA, Euclides da. Contrastes e confrontos. Rio de Janeiro: Record, 1975. (N. Ed.) 
Por motivo prático, situaremos $O s$ sertões considerando o cruzamento de três instâncias fundamentais: o sujeito narrador, a eclosão de um evento histórico e a presença de uma escrita singular. O núcleo central de nossa argumentação será dirigido pela idéia segundo a qual Os sertões possuem características de obra que ao se elaborar produziu a reconstituição de uma história aparentemente pronta ao Autor quando começou a contá-la. Enunciado de outra maneira, ao perseguir a ética dos princípios e a linguagem do compromisso, Euclides afastou-se do estereótipo e da (pré)concepção que o alimentavam antes de chegar em Canudos; graças à "traição da escrita", o que estava fadado à infâmia e à desmoralização ganhou o estatuto da dignidade.

\section{SUJEITO NARRADOR}

Euclides Rodrigues Pimenta da Cunha nasceu em Cantagalo, Rio de Janeiro, no dia 20 de janeiro de 1866 e morreu em 15 de agosto de 1909, aos 43 anos. No curto período de sua vida, conheceu a morte prematura da mãe, entrou na carreira militar, formou-se engenheiro, fez-se jornalista e viveu intensamente a efervescência republicana, seja apoiando o 15 de Novembro, seja amargando a decepção pelos rumos do movimento. A construção de uma "república do filhotismo" não era, certamente, o que Euclides da Cunha pretendia para o Brasil. Desde a Escola Militar da Praia Vermelha, o jovem cadete já demonstrava determinação no cumprimento de projetos e programas para o país.
Sob influência de Benjamim Constant, o futuro Autor de $\grave{A}$ margem da história levaria às últimas consequiências suas convicções republicanas confrontando-se contra a monarquia.

Por ocasião da visita do conselheiro Tomás Coelho, ministro da guerra do império, à Escola, Euclides atirou-lhe aos pés o sabre, revelando inconformidade com a presença daquela autoridade representante de D.Pedro II. Recolhido à prisão foi, posteriormente, excluído da carreira militar, para onde retornou, por tempo curto, apenas depois dos acontecimentos de 15 de Novembro de 1889. Na vida civil trabalhou como engenheiro e jornalista, em A Província de São Paulo, depois, O Estado de S. Paulo, matutino que o levaria, finalmente, ao sertão da Bahia para cobrir os eventos de Canudos.

Um homem de "linha reta", vivendo na "república dos medíocres" marcada pelos oportunistas sem projeto de futuro e que não desejavam indispor-se ou romper com as mazelas deixadas pelo latifúndio, haveria de conhecer uma série de dissabores pessoais e profissionais que o levariam a viver sob os imperativos da "engenharia errante", constantemente marcado por dificuldades financeiras. Mesmo quando chamado pelo então presidente da República há pouco inaugurada, Marechal Floriano Peixoto, para indicar o cargo que desejaria ocupar - Euclides era homem célebre pelas atitudes que tomara contra a Monarquia, além de ser genro do General 
Sólon, um respeitado militar a quem os companheiros confiaram entregar a carta de renúncia de Pedro II - respondeu o futuro autor d'Os sertões que apenas queria o que a lei lhe reservava, ou seja, um estágio como Engenheiro recém-formado junto à Estrada de Ferro Central do Brasil. Percebe-se que estamos falando de uma personalidade, cujo orgulho era o de nunca ter cedido princípios programáticos às determinações pragmáticas. Alguém que em nosso tempo correria o risco de ser trancafiado nalgum manicômio sob acusação de insanidade.

Euclides da Cunha orgulhava-se de não ser um "felizardo vadio", daí haver apontado os desmandos da "república coroada" contra as populações rurais. Anjo vingador dos que não tinham direito à voz, ajudou a romper com a mitologia romântica de que era possível existir convivência entre " $a$ 'ordem excludente' e o 'progresso comprometido' com o legado mais abominável do passado. Sua morte precoce foi um alívio para os césares"”

Inquieto e polêmico, o autor $\mathrm{d}^{\prime} \mathrm{O}$ s sertões sofreu influências do pensamento do século XIX. Algumas das doutrinas do tempo as seguiu por período mais longo, outras renegou durante percurso reflexivo, chegando a fundir de maneira ecumênica tendências diferentes, mas revelando sempre aquele espírito indagador de quem pretendia entender o drama brasileiro. Daí encontrarmos saudações e desabonos a Augusto Conte e ao positivismo, uma crença inicial nas teorias raciais, assim como uma entusiasmada recepção ao socialismo científico e a Marx. Com relação aos pensa- dores brasileiros, é possível reconhecer as influências de Joaquim Nabuco e Capistrano de Abreu, na História; Teodoro Sampaio e Orvile Derby nas Ciências Naturais; André Rebouças no planejamento e na tecnologia. Verdade que nem sempre tudo isto foi devidamente absorvido e ajustado em registros finos, até por conta de uma vida sem escrivaninha, de quem lia em lombo de burro, construindo estradas de ferro pelo país, ou viajando rio Amazonas acima para demarcar fronteiras no extremo norte. Entretanto, o gênio criador com sua escrita rebelde e irascível encarregou-se de produzir documento único cuja solidez e importância para a cultura brasileira fez-se maior do que eventuais diálogos transversos motivados por apreensão ligeira de conceitos em voga no final do século XIX.

\section{EVENTO HISTÓRICO}

Situar aspectos da biografia euclidiana importa para se compreender Os sertões, visto que apenas um perfil combativo e de sensibilidade rara poderia trazer à luz, com tanta percuciência, a expressão dramática das ocorrências em Canudos. Tratemos de modo mais próximo os eventos envolvendo um homem chamado Antônio Vicente Mendes Maciel, o Antônio Conselheiro, peregrino nascido em Quixeramobim, no Ceará, em 13 de março de 1830 (alguns autores registram 1828). A vida do Bom Jesus Conselheiro, como também era conhecido o missionário, está marcada por lendas e histórias. Dela interessa-nos apenas registrar o fato de que, tendo sido

2. SEVCENKO, Nicolau. O outono dos césares e a primavera da história. Revista USP. São Paulo: CCS/USP, n. 54, 2002. p.37. 
abandonado pela mulher, peregrinou uns 15 anos entre o Ceará, Pernambuco, Alagoas, Sergipe e Bahia. Aqui, em 1893, fixou-se num ermo ao norte, distante quase 400 quilômetros de Salvador, numa velha fazenda de gado chamada Canudos.

Os aproximados 600 acompanhantes que vagavam com o Santo Conselheiro e fundaram o lugar, rapidamente receberam a companhia de outras 2000 almas, que alcançaram 20.000 quando ocorreu a destruição em 1897.

Rebatizada de Belo Monte, por Antônio Conselheiro, olocus passou a receber gente que para lá se dirigia por variadas razões: a fuga do poder despótico dos coronéis ou de pendências com a justiça do chamado mundo legal, pronta, naquele fim de mundo, para favorecer os poderosos; a busca de formas alternativas de vida; a procura por salvação espiritual - a cidadela possuía, também, característica de facilitar a espera messiânica. Terra da promissão, espaço da felicidade suprema, ou, simplesmente, "Imunda antesala do céu", como a considerava Euclides da Cunha nas páginas iniciais d'Os sertões.

Colocado na perspectiva do tempo, é possível afirmar que o ideário meio confuso de Antônio Conselheiro, baseado nos ensinamentos do Velho Testamento, era menos ativamente contra alguma coisa e mais a favor da manutenção de um espaço religioso que abrigasse os excluídos de diversos matizes e onde fosse possível viver a verdadeira fé, aquela que deixara de existir além de Canudos. No "mundo de fora", tomado pelo reformismo religioso, pela separação doEstado e da Igreja e pela (ré)pública, imperava o mal e a desesperança.

E assim, provavelmente, teria permanecido por mais tempo não fosse a precipitação de incidentes que terminaram com uma das maiores tragédias de que se tem notícia no país. Por razões distintas, o que ocorria às margens do rio Vaza-Barris provocava a ira dos grandes proprietários de terras, que viam no exemplo de Canudos perigo para a manutenção dos latifúndios; da igreja, por reconhecer que um "herético" tinha mais força e penetração popular do que os clérigos que professavam a palavra oficial do catolicismo; dos republicanos, que movidos por distintos interesses difundiam a idéia de existir em Canudos insurgência contra a ordem. Ademais, publicistas de grandes jornais incitavam o envio de tropas para acabar com os conselheiristas.

Em 21 de novembro de 1896, o juiz Arlindo Leoni, de Juazeiro, enviou uma tropa de 107 homens, comandada pelo tenente Pires Ferreira, para deter o Conselheiro. Os canudenses impuseram derrota aos invasores e provocaram a ira definitiva do Estado. Nos primeiros dias de janeiro de 1897, 560 soldados, sob comando do major Febrônio de Brito, tentaram atacar Belo Monte, sendo igualmente derrotados; depois de pesadas baixas, a 2 . $^{\text {a }}$ expedição bateu em retirada. Ante o crescendo dos fracassos, formou-se nova expedição, sob comando do temível cortador de gargantas, coronel Moreira César. Com este herói da guerra do Paraguai seguiram 1.300 soldados, além de farta munição e modernos canhões Krupp. Ordenando desastrada carga de cavalaria contra o lugare- 
jo, Moreira César, que dizia só temer a "fuga dos fanáticos", tombou morto nas primeiras escaramuças, e a $3 .^{a}$ expedição foi quase toda dizimada. O fato comoveu o país por envolver Moreira César e os brios do exército republicano. Mais uma expedição foi rapidamente preparada, já em março de 1897 , reunindo 10.000 homens. Ao final dos combates, em outubro, havia em torno de 20.000 canudenses mortos.

É neste cenário que nascerá Os sertões.

\section{ESCRITA SINGULAR}

1

A redação d'Os sertões ocorreu entre 1898 e 1902, quase todo ele em São José do Rio Pardo, cidade para onde Euclides da Cunha havia se transferido para reconstruir uma ponte. $\mathrm{O}$ livro foi oficialmente lançado em 2 de dezembro de 1902 pela editora Laemmert, do Rio de Janeiro.

O texto final é, contudo, uma retomada de artigos e anotações que o escritor havia produzido em decorrência dos eventos canudenses, escritos antes da viagem ao interior baiano, caso da série $A$ nossa Vendéi ${ }^{3}$, saída em O Estado de S. Paulo em março e julho de 1897 , ou do material elaborado já na frente de batalha e, parte dele, também posto em circulação pelo matutino paulista. Euclides procedeu, ainda, à leitura de textos enviados por correspondentes de outros jornais que estavam ou haviam estado no palco dos acontecimentos.

O impacto do livro decorreu não apenas da revelação do drama sertanejo desconhecido dos habitantes das grandes cidades costeiras do Brasil, sobretudo do Rio de Janeiro, ao tempo/centro do poder político e da vida intelectual, mas também pelo exercício de uma linguagem pouco usual, em seu conjunto de novidades técnicas, passagens poéticas, idiomatismos, exploração de figuras de linguagem, de tensões entre o ensaio e o romance, a história e a ficção. Esta inusitada combinação retórica que compreendia o uso de termos científicos regidos por uma grandiosidade "condoreira", como se Vitor Hugo estivesse escrevendo sob influência de Taine, Darwin, Lombroso, Spencer, permitiu repensar a própria questão dos gêneros textuais.

Os sertões fazem parte de uma linhagem de obras onde poderiam ser incluídas, por exemplo ${ }^{4}$, A divina comédia, de Dante Alighieri e $O$ coração das trevas, de Joseph Conrad. Euclides passou quatro anos organizando as anotações que havia trazido da "região assustadora" e de onde sairá deprimido e doente ${ }^{5}$. O horror presente em Os sertões ecoa, também, da garganta torturada do enlouquecido comerciante de marfim Kurtz - per-

3. Vendéia, região na França que em 1793 conheceu uma revolta que opunha camponeses e restauracionistas à revolução. O termo comparativo entre Canudos e a Vendéia, indica a crença inicial de Euclides da Cunha na existência de um movimento conservador, religioso, que desejava a volta de D.Pedro II, portanto inimigo da "revolução" republicana. 4. ALIGHIERI, Dante. A divina comédia. São Paulo: Martin Claret, 2002.

CONRAD, Joseph. O coração das trevas. São Paulo: L\&PM, 1998. (N. Ed.)

5. Situação idêntica à vivida por um outro correspondente de guerra, o capitão honorário do exército, Manuel Benício, que ficará em Canudos entre junho e julho, produzindo reportagens para o Jornal do Commércio, do Rio de Janeiro. Pelo tom crítico do material que elaborou, Benício foi excluído dos quadros do Clube Militar. Em 1889 publicou livro importante sobre o episódio, $O$ rei dos jagunços. É perceptível em Os sertōes a leitura que Euclides fez de Benício, ainda que não $o$ cite. 
dido na selva do Congo e sendo caçado pelo inglês Marlow - personagem de $O$ coração das trevas, a inquietante metáfora sobre a presença do colonialismo inglês no século XIX. Se em ambos os textos a imagem do inferno está presente, isto ocorre naquela dimensão dantesca da "selva selvagem". Guiado por Virgílio, Dante tem que atravessar os círculos demoníacos, para, só então, poder alcançar os patamares do purgatório e do Paraíso:

"Ah! Descrever não posso esta espessura, esta selva selvagem, densa e forte, que em relembrá-la a mente se tortura!". 6

\section{2}

É importante ler Os sertões reconhecendo o caráter tenso e contraditório de sua escrita. Ao dirigir-se para Belo Monte, o nosso Autor estava ainda impregnado daquele primeiro espírito republicano que considerava Antônio Conselheiro um agente da monarquia. Os primeiros textos que envia da frente de batalha e os registros da Caderneta de Campo denotam uma percepção do fenômeno que não se diferenciava muito do tom geral condenatório da maioria da imprensa. Essa via com extrema má vontade o povo de Canudos. Entretanto, o contato com o sertanejo, o testemunho da crueldade e da violência praticada contra Belo Monte, a verificação da falta de sentido em se fuzilar e degolar prisioneiros, o espanto com a carnificina, o genocídio e a insensibilidade do governo para reconhecer as particularidades de um mundo marcado pela fome e pela miséria operaram mudanças na perspectiva euclidiana com reflexos na feitura de Os sertões.

\section{3}

O livro foi elaborado na integração de três partes: a terra, o homem e a luta. Esquema de fundo determinista desejoso de apreender a totalidade dos eventos considerando os fatores ambientais, antropológicos e históricos que os condicionam. Tal estrutura, conquanto organize o livro, na prática é flexibilizada graças a uma escrita que se revelará maior do que a fórmula proposta.

Fixemos alguns exemplos disto que chamamos flexibilização interna da obra. Destaquemos, na parte referente ao homem, a presença das teorias raciais do século XIX, todas elas orientadas na perspectiva de que a história da humanidade registra o domínio das raças fortes sobre as fracas. Sendo assim, a miscigenação racial é tratada negativamente: "A mestiçagem extremada é um retrocesso" $(77)^{7}$, daí estarmos condenados a não ter unidade racial e não a "...teremos, talvez, nunca”(51). Por esta óptica, o sertanejo, como uma sub-raça, produto de múltiplos cruzamentos, representaria a involução biológica, a negação do progresso, incapaz seria de absorver as grandes transformações civilizatórias. Eo drama, segundo o Euclides das páginas iniciais, é o de que "Estamos condenados à civilização. Ou progredimos, ou desaparecemos"(52).

Note-se que havia uma transposição dos modelos da Biologia e das Ciências Na-

6. Aproximações entre Dante e Euclides podem ser lidas em VENTURA, Roberto. Euclides da Cunha no vale da morte. Revista USP. São Paulo: CCS/USP, n. 54, 2002.

7. As citaçōes d'Os sertōes foram retiradas da 29." ed. Rio de Janeiro/Brasília, Francisco Alves/INL, 1979. Entre parênteses estão os números das páginas. 
turais para os estudos da sociedade e da cultura. Assim, se existe indefinição étnica, a nação deve responsabilizar-se por superá-la introduzindo padrões de cultura e civilização dificultados pelos cruzamentos raciais. Entende-se porque, num certo momento, Euclides e muitos dos seus contemporâneos reconheciam nos ataques contra Canudos o esforço para se remover os entraves ao progresso.

A certa altura, entretanto, leremos em $O s$ sertões: "O sertanejo é, antes de tudo, um forte. Não tem o raquitismo exaustivo dos mestiços neurastênicos do litoral" (91).

\section{$\mathrm{O}$ autor parece tropeçar diante} de um conjunto de teorias que absorvera sem grande profundidade e que tratara de aplicar na fatura do seu livro. $\mathrm{O}$ resultado é um ecletismo muitas vezes confuso e contraditório.

Para explicar aquela célebre frase, estabelece um engenhoso conjunto de argumentos que não resistem à análise mais cuidadosa. Ele considera existirem diferenças entre o mestiço do sertão e do litoral. O primeiro ficou livre da carga civilizatória da cultura "superior". Isolado, perdido nas caatingas, longe das cidades e dos seus modos de vida, recebeu impacto menor daquela cultura, por isso não decaiu. É apenas um retrógrado. $\mathrm{O}$ segundo, vivendo nas grandes cidades, em contato com formas de vida e cultura que não consegue absorver por não ter estrutura mental ágil e desenvolvida, sofreu o peso deste processo e sucumbiu, degene- rando-se. Quer dizer, o sertanejo é um sobrevivente: é forte porque conseguiu, de um lado, adaptar-se a um meio difícil e inóspito, por outro, não recebeu os impactos da civilização que levaram à decadência física e moral do mestiço costeiro.

Daí as célebres antíteses do sertanejo. Trata-se de um Hércules/Quasímodo, um guerreiro combativo e valente, porém feio, mirrado, estranho. A aparência enganadora faz que diante dos desafios este homem se transfigure: “(...) e da figura vulgar do tabaréu canhestro, reponta, inesperadamente, o aspecto dominador de um titã acobreado e potente, num desdobramento surpreendente de força e agilidade extraordinária" (81).

Este tipo é dos brasileiros: “(...) o mais tenaz; é mais resistente; é mais perigoso; é mais forte; é mais duro" (84).

$\mathrm{E}$, ao final, o sertanejo passa a ser visto como: "a rocha viva da nossa raça" (398).

Poderíamos prosseguir neste diapasão confrontando a visão inicial de Canudos como um lugar de bandidos afeitos ao misticismo de um doido, até as páginas finais, quando o lugar e sua gente ganham a condição de terra de heróis. Vejamos, em seguida, esta dinâmica paradoxal: "Canudos era o homízio de famigerados facínoras. Ali chegavam, de permeio com os matutos crédulos e vaqueiros iludidos, sinistros heróis da faca e da garrucha. E estes foram logo os mais quistos daquele homem singular, os seus ajudantes de ordens prediletos, garantindo-lhe a autoridade inviolável" (130). E, quase duzentas páginas depois: "Sucedeu, então, um fato extraordinário de todo em todo imprevisto. O inimigo desairado revivesceu com vigor incrível. Os combatentes, que o en- 
frentavam desde o começo, desconheceram-no. Haviam-no visto, até aquele dia, astucioso, negaceando na maranha das tocaias, indomável na repulsa às mais valentes cargas, sem par na fugacidade com que se subtraía aos mais improvisos ataques. Começaram a vê-lo heróico" (375).

\section{4}

A parte final d'Os sertões precipita cenas absolutamente dramáticas. A força da escrita euclidiana põe em cheque a nobreza dos princípios civilizatórios, da superioridade do litoral sobre o sertão, para revelar a face de um crime contra a nacionalidade. As bananas de dinamite, os canhões, a metralha, os galões de querosene usados para explodir e queimar Canudos, transformaram-se, no livro de Euclides da Cunha, em símbolos de um metódico exercício destruidor: a tecnologia moderna experimentando os avanços científicos em casebres perdidos no fim do mundo. As últimas páginas da obra são cortadas por gritos assustadores, rolos de fumaça, corpos em decomposição, sibilos de projéteis, odores irrespiráveis, batidas da banda marcial anunciando vitória, hasteamento da bandeira nacional no meio da praça vencida indicando ao resto do país que o território rebelde estava anexado à República.

Decidido a escrever o livro esclarecedor sobre "esta fase obscura da nossa História", aquela que falando da rendição de Antônio Beato não explica o porquê de seu desaparecimento: "E de que modo comentaríamos, com a só fragilidade da palavra humana, o fato singular de não aparecerem mais, desde a manhã de 3 , os prisioneiros válidos colhidos na véspera, e entre eles aquele Antô- nio Beatinho que se nos entregara confiante(...)". Euclides produz nesta passagem uma das peças mais contundentes sobre os paradoxos da chamada marcha civilizatória. Outros similares podem ser encontrados no processo de colonização que custou o desaparecimento de povos indígenas, nas guerras de conquista, no avanço da barbárie nazifascista. Enfim, não faltam exemplos.

Através da leitura d'Os sertões
ficamos sabendo que Belo
Monte desapareceu, os
moradores morreram, a vida
cessou. O que havia surgido
para ser um lugar de paz e
salvação viu-se transformado
num vasto cemitério animado
pelo anjo do mal.

Canudos imolou-se "Exemplo único em toda a História, resistiu até ao esgotamento completo. Expugnado palmo a palmo, na precisão integral do termo, caiu no dia 5 , ao entardecer, quando caíram os seus últimos defensores, que todos morreram".

O corpo de Antônio Conselheiro foi descoberto numa cova rasa, a cabeça decepada remetida à Faculdade de Medicina da Bahia, onde, examinada pelo médico Nina Rodrigues, é considerada isenta de loucura. Escreve aquele afamado cirurgião e antropólogo: "O crânio de Antônio Conselheiro não apresenta nenhuma anormalidade que demonstre traços de degenerescência...É um crânio normal"8.

8. RODRIGUES, Nina. As coletividades anormais. Rio de Janeiro: Civilização Brasileira, 1939. p.131-3. 
O Exército volta para casa sendo ovacionado pela multidão nas principais capitais do país. O perigo mestiço fora afastado. Doravante...

Canudos seria apenas História. Não uma história qualquer, mas esta produzida entre a sucessão de eventos e a subjetividade da escrita. É graças a este movimento onde tanto se fornece a cronologia dos últimos dias de Canudos, o número de seus derradeiros resistentes, a quantidade de casas destruídas, etc., como opera-se com metáforas, metonímias e antíteses que se tornará possível criar um quadro ao mesmo tempo trágico e grandioso, dramático e heróico. Aqui não falta sequer o recurso à ironia para mostrar-se que o genocídio poderia ter sido evitado. Antônio Conselheiro, aquele mesmo que nas primeiras páginas d'Os sertões era chamado de facínora, louco, bárbaro agitador, agora é tratado de forma inegavel- mente respeitosa. Ei-lo, o "terribilíssimo antagonista", sendo removido da cova onde fora enterrado poucos dias antes, envolto num velho hábito de brim americano, esquálido, olhos fundos cheios de terra e vigiado por dez mil botas do Exército. Os triunfadores, numa operação mórbida e bárbara que havia custado entre os canudenses mais de vinte mil vidas, recolheram aquele que viria a ser seu único troféu: a cabeça meio decomposta de Antônio Conselheiro. Estranhos vencedores, especialíssimos missionários da civilização e do progresso.

O livro de Euclides da Cunha é ao mesmo tempo uma grandiosa aventura da linguagem e uma denúncia do crime que a nacionalidade praticou contra ela mesma. Atualizar os sentidos gerados em Os sertões é uma forma de evitar que a história se repita como farsa ou como nova tragédia. ${ }^{9}$
Resuma. $\mathrm{O}$ artigo propõe uma reflexão sobre a obra Os sertôes, de Euclides da Cunha. Reflexão estruturada em três aspectos: o sujeito narrador; o evento histórico e a escrita singular. $\mathrm{O}$ autor do artigo destaca a dinâmica interna da obra, que completa 100 anos, como reveladora do processo de transformação do homem Euclides da Cunha e de sua visão sobre o massacre, à medida que sua sensibilidade de homem correto toma contato com o drama dos sertanejos. Esse diálogo interno do autor, sua obra e a história permanece como grande valor de Os sertôes, reflexão necessária para a atualidade.

Palavras-chave, Os sertôes, Euclides da Cunha, Canudos, sertanejo, Brasil
(Os sertões: a 100-year old educational epopee) Abstract. The article proposes a reflection on $O S$ sertões, by Euclides da Cunha, based on three aspects: the narrator subject; the historical event; and the unique writing style. The article's author highlights the book's internal dynamics, which is now 100 years old, as revealing of the transformation process the man Euclides da Cunha was undergoing and of the view of the massacre, as his sensibility changes, as a proper man, as he contacts the drama of the hinterland people. The author's internal dialogue, his work and his history remain the major value of Os sertôes, a reflection that is necessary for these days.

Key words. Os sertôes, Euclides da Cunha, Canudos, hinterland people, Brazil

9. Bibliografia de apoio: ANDRADE, Olímpio de Sousa. História e interpretação de Os sertões. São Paulo: Edart, 1966. CITELLI, Adílson. Roteiro de Leitura. Os sertões de Euclides da Cunha. São Paulo: Ática, 1996. 